\title{
Neoparamoeba branchiphila infections in moribund sea urchins Diadema aff. antillarum in Tenerife, Canary Islands, Spain
}

\author{
Iva Dyková1, 2,*, Jacob Lorenzo-Morales ${ }^{3,4}$, Martin Kostka ${ }^{1,2}$, Basilio Valladares ${ }^{3}$, \\ Hana Pecková ${ }^{1}$ \\ ${ }^{1}$ Institute of Parasitology, Biology Centre, Academy of Sciences of the Czech Republic, Branišovská 31, \\ 37005 České Budějovice, Czech Republic \\ ${ }^{2}$ Faculty of Science, University of South Bohemia, 37005 České Budějovice, Czech Republic \\ ${ }^{3}$ University Institute of Tropical Diseases and Public Health of the Canary Islands, 38207 University of La Laguna, Tenerife, Spain \\ ${ }^{4}$ Centre for Integrative Physiology, School of Biomedical Sciences, University of Edinburgh, Hugh Robson Building, \\ George Square, Edinburgh EH8 9XD, UK
}

\begin{abstract}
A total of 109 sea urchins from 3 species collected in 2 localities off the coast of Tenerife Island, Spain, were examined for the presence of free-living amoebae in their coelomic fluid. Amoeba trophozoites were isolated exclusively from moribund individuals of long-spined sea urchins Diadema aff. antillarum (Philippi) (Echinoidea, Echinodermata) that manifested lesions related to sea urchin bald disease on their tests (16 out of 56 examined). No amoebae were detected in Arbacia lixula (L.) and Paracentrotus lividus (Lamarck). From the former sea urchin species, 8 strains, established from 10 primary isolates, were identified as Neoparamoeba branchiphila Dyková et al., 2005 using morphological and molecular methods. Results of this study (limited to the screening for freeliving amoebae) together with data on agents of sea urchin mortalities reported to date justify the hypothesis that free-living amoebae play an opportunistic role in $D$. aff. antillarum mortality. The enlargement of the dataset of SSU rDNA sequences brought new insight into the phylogeny of Neoparamoeba species.
\end{abstract}

KEY WORDS: Neoparamoeba $\cdot$ Diadema aff. antillarum $\cdot$ SSU rDNA phylogeny $\cdot$ Tenerife

\section{INTRODUCTION}

Amoebae of the genera Paramoeba Schaudin, 1896 and Neoparamoeba Page, 1987 are free-living organisms that are also known as pathogens of marine fish and invertebrates. Species of these 2 genera are very similar in terms of features such as the morphotype of trophozoites and ultrastructure, including their kinetoplastid endosymbionts. The microscales described on the cell surface of Paramoeba eilhardi Schaudin, 1896 by Grell \& Benwitz $(1966,1970)$ distinguish Paramoeba from Neoparamoeba (Page 1987).

The amount of morphological and molecular data collected on Neoparamoeba species from extensive studies on aetiology of amoebic gill disease (AGD) of marine fish far exceeds our knowledge of Paramoeba spp. Except for $P$. eilhardi isolated by Grell in 1960 in Villefranche, France (Grell 1961), no strain of Paramoeba sensu Page 1987 is available in culture collections. Although several disease outbreaks in marine invertebrates have been attributed to Paramoeba spp., subsequent revisions of published data reveal that neither $P$. perniciosa, described as the agent of 'gray crab disease' (Sprague \& Beckett 1968, Sprague et al. 1969, Perkins \& Castagna 1971, Johnson 1977), nor P. invadens, considered to cause mortalities of green sea urchins (Jones 1985, Jones \& Scheibling 1985), meets the definition given for Paramoeba by Page (1987). 
Similarly, Mullen et al. (2004), who originally described 'paramoebiasis' of American lobster, later assigned the amoebae considered the primary cause of the 1999 lobster mass mortality to Neoparamoeba pemaquidensis (see Mullen et al. 2005). Aetiological conclusions mentioned above, inconsistencies persisting in the literature on amoebic diseases of invertebrates (Scheibling et al. 2010), and the scarcity of reliable data on Paramoeba spp. stimulated our interest in isolation of species of this genus and subsequent phylogenetic analysis of Paramoeba and Neoparamoeba strains. We took the opportunity to combine our research interests with those of a research team from the Department of Marine Biology at the University of La Laguna, Tenerife, Canary Islands, Spain, involved in monitoring the population and health status variations of sea urchins in the island as well as the biodiversity and ecology of sea urchins habitats. Results based on examination for amoebae of both asymptomatic and diseased sea urchins collected along the coasts of Tenerife Island are presented in this study.

\section{MATERIALS AND METHODS}

Collection of sea urchins. In April 2010, a total of 109 sea urchins from 3 species, the long-spined sea urchin Diadema aff. antillarum (Philippi) $(\mathrm{n}=56)$, the black sea urchin Arbacia lixula (L.) ( $=29$ ), and the purple sea urchin Paracentrotus lividus (Lamarck) $(\mathrm{n}=24)$ were collected and examined from 2 localities off the coast of Tenerife Island (Abades $28^{\circ} 08^{\prime} 26^{\prime \prime} \mathrm{N}, 16^{\circ} 26^{\prime} 04^{\prime \prime} \mathrm{W}$; Boca Cangrejo $28^{\circ} 24^{\prime} 22^{\prime \prime} \mathrm{N}$, $16^{\circ} 18^{\prime} 52^{\prime \prime} \mathrm{W}$ ) in which sea urchins showed signs of disease. Sea urchins were picked up from the seafloor at low tide by divers, transported immediately to the laboratory, and kept for a short time in aquarium tanks supplied with running seawater sterilized by UV light. The set of collected sea urchins contained specimens with pronounced disease symptoms (i.e. loss of spines, eroded areas, or small holes on their tests), as well as specimens of healthy appearance.

Isolation and culture of amoebae. Screening for the amoeba infections was restricted to the coelomic fluid of sea urchins sampled after the seawater was drained away from their mouth area and spiny surface. An $18 \mathrm{G} \times 1 \frac{1}{2}{ }^{\prime \prime}$ needle was inserted through the peristomal membrane at an angle that avoided contact with the lantern area, and a small volume of coelomic fluid (up to $5 \mathrm{ml}$ from big specimens) was withdrawn into a sterile, disposable syringe. A total of 3 to 4 drops of coelomic fluid was placed on the surface of nonnutrient seawater agar prepared from sterilized seawater of the same origin as the sea urchins. Inoculated agar plates ( 3 per sea urchin individual) were stored upside-down in an air-conditioned laboratory $\left(20^{\circ} \mathrm{C}\right)$. In order to detect primary isolates of amoebae as soon as possible and to avoid overgrowth with bacteria, agar plates were checked several times over the first week post-sampling. The handling of primary isolates, culture methods, and harvesting for ultrastructural and molecular studies were the same as those previously described (Dyková et al. 2000, 2005). Within the set of 109 sea urchins examined, 15 individuals (12 Diadema aff. antillarum and 3 Arbacia lixula) were moribund, and their body surface showed eroded areas devoid of spines. In total, 10 primary isolates were obtained (all those from coelomic fluid of moribund specimens of Diadema aff. antillarum), but 2 were lost due to bacterial overgrowth. We established strains from the remaining 8 isolates, which are characterized in this study using morphological and molecular methods.

Microscopy. Both light and electron microscopy was carried out as described elsewhere (Dyková et al. 2000, 2005). Trophozoites of isolated strains were observed in hanging drop preparations and documented using an Olympus BX51 equipped with Nomarski optics and DP70 digital camera. For electron microscopy, trophozoites were fixed on the surface of agar plate with cacodylate-buffered $3 \%$ glutaraldehyde, pelleted by centrifugation, postfixed with $1 \%$ osmium tetroxide, and embedded in Spurr resin after dehydration with acetone. Transmission electron microscope observations of ultrathin sections were accomplished with a JEOL JEM 1010 electron microscope operating at $80 \mathrm{kV}$. Images were collected with Megaview II soft imaging system using analySIS software.

DNA extraction, amplification and sequencing. Genomic DNA was extracted from pelleted trophozoites on culture day 4 or 5 using the JETQUICK Tissue DNA Spin Kit (Genomed) according to the manufacturer's protocol. The PCR amplification of SSU rRNA genes of Neoparamoeba strains and Perkinsela amoebae-like organisms was performed as described previously (Fiala \& Dyková 2003, Dyková et al. 2008). The amplified products were gel-purified and cloned into pDrive Cloning Vector using the QIAGEN PCR Cloning Kit (Qiagen). Sequencing was carried out on an automatic sequencer $\mathrm{ABI} 3130 \times 1$ using the $\mathrm{ABI}$ PRISM BigDye ${ }^{\circledR}$ Terminator v3.1 Cycle Sequencing Kit (Applied Biosystems).

Phylogenetic analyses. A total of 8 SSU rDNA sequences generated for this study and another 39 selected sequences of Neoparamoeba spp., Paramoeba eilhardi, and 8 outgroups were used to create an alignment by ClustalX version 2.0.6 (Larkin et al. 2007). The alignment comprising all these sequences was then manually checked in BioEdit (Hall 1999) for ambiguously aligned positions, which were deleted. The final alignment contained 1932 positions. The program 
RAxML version 7.0.3 (Stamatakis 2006) was used to compute the maximum likelihood (ML) tree with the general time reversible (GTR) model with gammadistributed rare heterogeneity and rapid bootstrapping (1000 replicates). Maximum parsimony (MP) trees and trees computed with the Fitch-Margoliash method with LogDet distances (LD) were computed in the program PAUP* version 4.0b10 (Swofford 2003). In both cases, heuristic searches were conducted with 1000 independent searches starting from trees constructed by random taxa addition. For tree arrangements the tree bisection and reconnection (TBR) algorithm was used. To check the robustness of the resulting MP and LD trees, 1000 bootstrap replicates were analyzed (with only 10 random starting trees). Bayesian analysis (BA) was performed with MrBayes version 3.1.2 (Ronquist \& Huelsenbeck 2003). Four simultaneous Markov chains Monte Carlo were run for $10^{6}$ generations with sampling frequency 100 generations and burnin 2500 (after checking for the plateau of -lnL by plotting it vs. generation).
To calculate \% identities of Neoparamoeba SSU rDNA sequences, another alignment of 42 sequences was prepared in ClustalX. It contained all Neoparamoeba SSU rDNA sequences used for phylogenetic analyses, with the exception of EU331036, AY714364, AY686575, EF474478, and EF474480, which were shorter than the rest. The alignment was trimmed to $2135 \mathrm{bp}$, and the sequence identity matrix was computed in BioEdit.

\section{RESULTS}

\section{Light microscopy and ultrastructure of isolated amoebae}

Trophozoites of amoeba strains were isolated exclusively from moribund long-spined sea urchins. Although a total of 109 sea urchins were subjected to isolation attempts, we failed to isolate a strain of Paramoeba sensu Page 1987. Trophozoites of all strains exhibited the same light microscopical features regard-

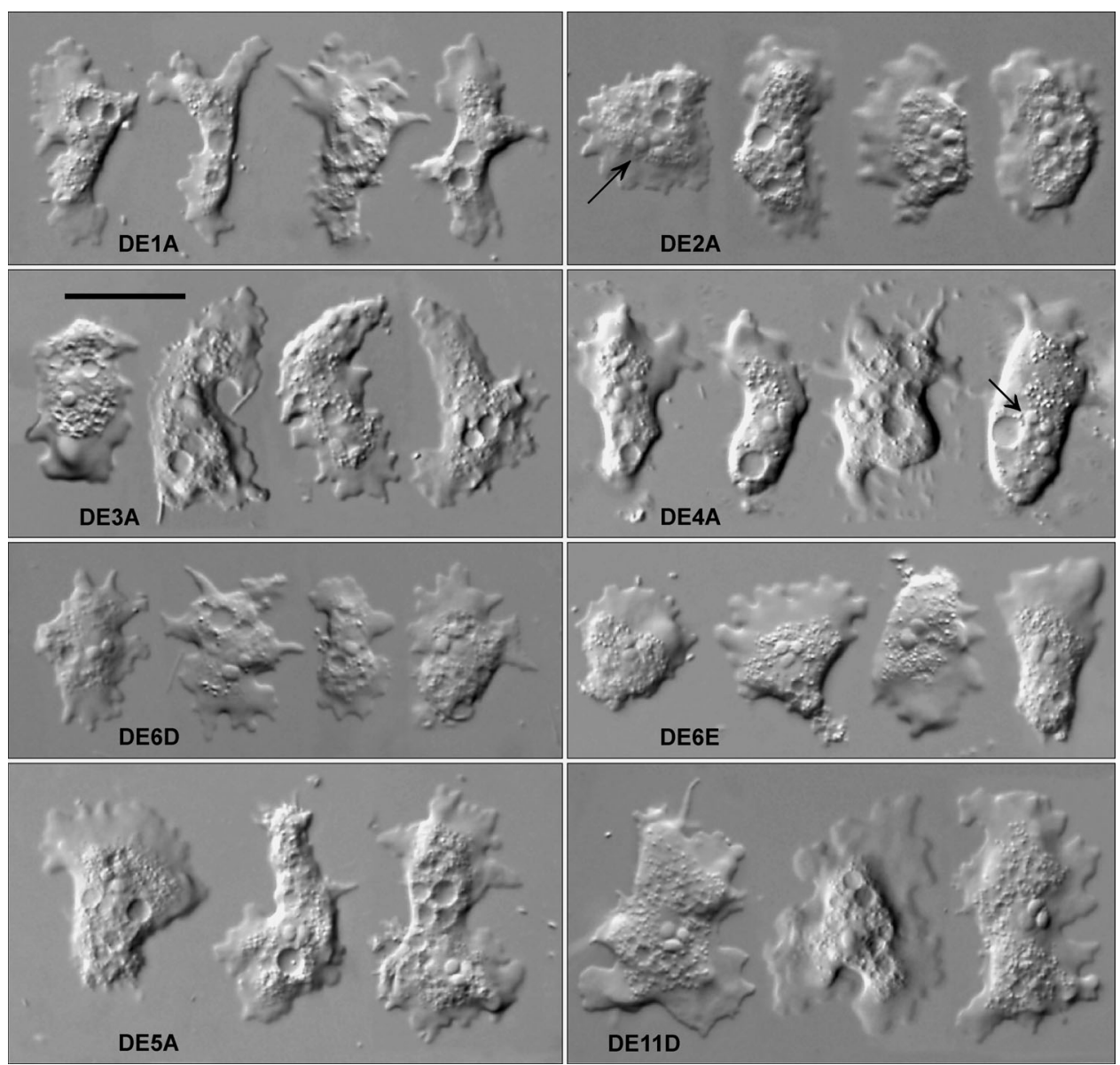

Fig. 1. Neoparamoeba branchiphila from Diadema aff. antillarum. Trophozoite representatives of N. branchiphila strains isolated from sea urchins $D$. aff. antillarum as seen in Nomarski differential interference contrast microscopy. Images are marked with strain codes also used in Fig. 7. Arrow marks 3 Perkinsela amoebae-like symbionts. Scale bar (for all panels) $=20 \mu \mathrm{m}$ 
less of local origin of sea urchins (Fig. 1). They were flattened with a narrow zone of hyaloplasm and short blunt projections extending from it. One to three pronounced bodies (endosymbionts) joined the nucleus located in vacuolated granuloplasm. When measured in the same stage of subculturing, the average length of trophozoites reached $30 \mu \mathrm{m}$ in all strains under study.

The fine structure of trophozoites observed in more than 100 sections fully corresponded to the diagnosis of Neoparamoeba given by Page (1987) and it was also absolutely consistent with the fine structure previously described for Neoparamoeba strains isolated from fish and invertebrates (Dyková et al. 2007). The overview of fine structure of the cell surface discriminating these newly isolated Neoparamoeba strains from Paramoeba, is presented in Figs. 2 to 6. Also comparisons of the ultrastructure of the kinetoplastid endosymbionts showed them to be identical to Perkinsela amoebaelike organisms (PLOs) as described in Hollande (1980) and Dyková et al. (2008).

\section{Molecular characterization of isolated strains}

The lengths of the 8 new SSU rDNA sequences of Neoparamoeba strains were 2008 to 2090 bp, with the exception of DE11D strain (2101 bp). These sequences as well as sequences of endosymbionts, i.e. PLOs of 2 Neoparamoeba strains, are deposited in GenBank database under accession numbers HQ132923HQ132930 and HQ132931-HQ132932, respectively.

The 2 PLO SSU rDNA sequences isolated from DE11D and DE4A Neoparamoeba strains were blasted against the nucleotide collection of NCBI (http://www. ncbi.nlm.nih.gov/). The former sequence was most similar to SSU rDNA of PLO isolated from SM68 $($ EU331011; $99 \%$ identity, Expect value $=0.0)$, the latter to SSU rDNA of PLO isolated from AFSM3 strain (AY163355; 98\% identity, Expect value $=0.0)$. Next best hits were, in both cases, SSU rDNAs of PLOs isolated from other strains belonging to the respective subclade (see Fig. 7) of $N$. branchiphila. The results are
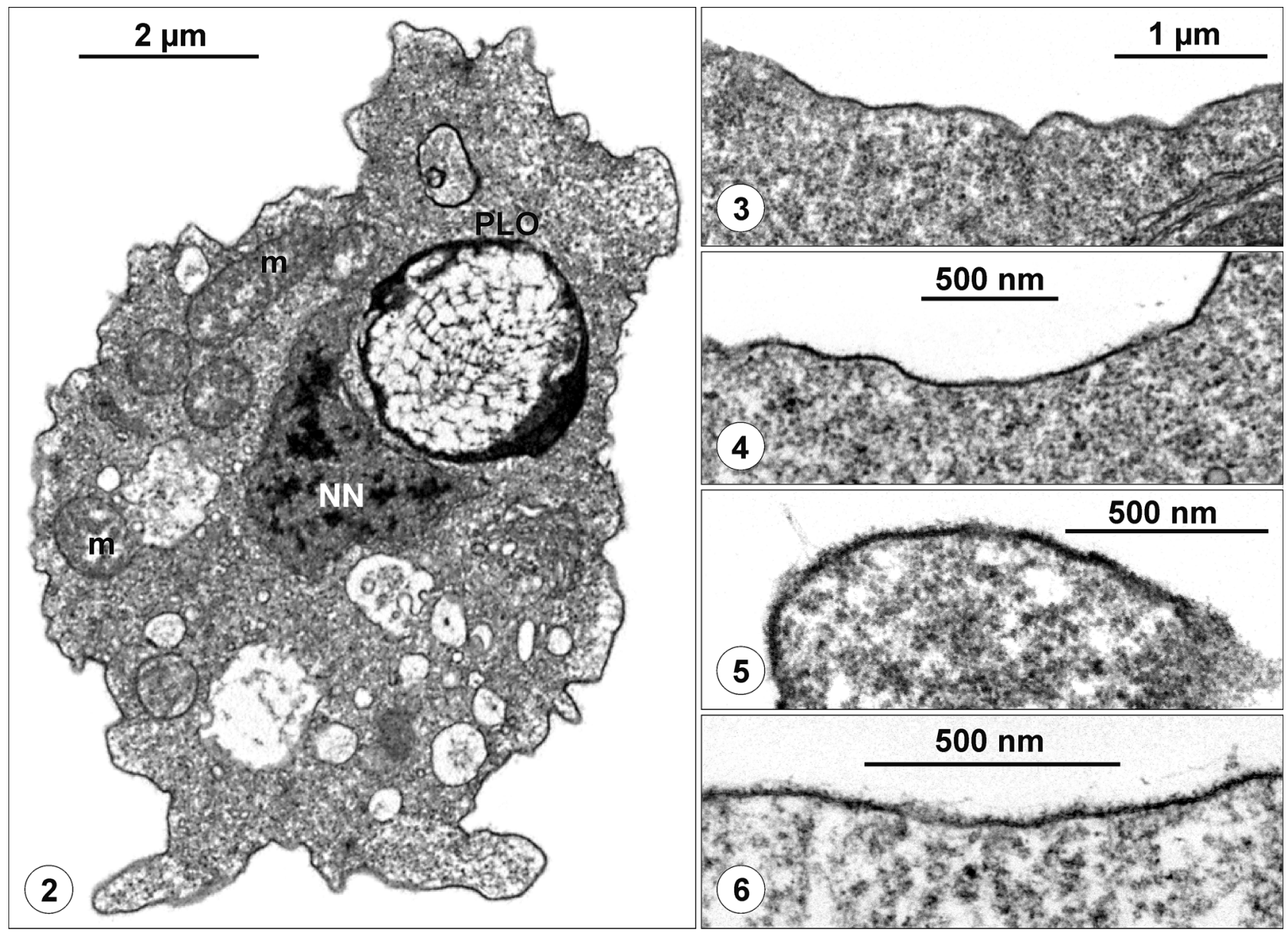

Figs. 2 to 6. Neoparamoeba branchiphila and Diadema aff. antillarum. Trophozoites of N. branchiphila isolated from sea urchins D. aff. antillarum and details of their ultrastructure. Transmission electron microscopy. Fig. 2. Trophozoite of N. branchiphila with nucleus (NN), mitochondria (m), and Perkinsela amoebae-like symbiont (PLO) in close vicinity of the nucleus. Bipolarly symmetrical PLO was sectioned at the level of its kinetoplastid DNA network. Figs. 3 to 6. Examples of trophozoite cell surface with amorphous glycocalyx 
thus in agreement with hypothesis of coevolution of amoebae and their symbionts (Dyková et al. 2008).

\section{Phylogenetic analyses}

Phylogenetic analyses assigned all strains isolated from coelomic fluid of moribund Diadema aff. antillarum to Neoparamoeba branchiphila (Fig. 7). The result was well supported by all 4 methods applied. The SSU rDNA sequences of $N$. branchiphila divided into 2 well-supported clusters. Seven of our new sequences grouped in the same cluster, within the strains of $N$. branchiphila; only strain DE11D was grouped in the other cluster. Phylogenetic affinities of the 2 PLO sequences (isolated from DE11D and DE4A) revealed by BLAST have clearly shown that these 2 PLOs are most closely related to PLOs isolated from other Neoparamoeba strains of the same $N$. branchiphila lineage.

Two notable features of the topology are: (1) the position of Paramoeba eilhardi well within Neoparamoeba as a sister taxon to $N$. perurans and (2) the possibility that $N$. pemaquidensis is paraphyletic ( $N$. aestuarina being its ingroup). The latter result, namely the sister position of $N$. aestuarina and $N$. pemaquidensis AVG8194 strain, has rather high support from ML (88\% bootstrap) and BA (posterior probability = 1), but LD strongly supports both species as monophyletic (more than 99\% bootstrap in both cases). In any case, the 2 species are closely related, as further suggested by high \% identities of their SSU rDNA sequences. Average sequence identities among and within Neoparamoeba species are given in Table 1.

Fig. 7. Maximum likelihood tree based on SSU rDNA sequences of 47 Neoparamoeba + Paramoeba strains and 8 amoebozoa outgroups. Our new sequences of Neoparamoeba branchiphila are shown in bold. Bootstrap values for maximum likelihodd, LogDet distances, and maximum parsimony and Bayesian posterior probabilities are given at the nodes, respectively. Asterisks indicate bootstraps lower than $50 \%$; nodes with black dots obtained bootstrap support of $99 \%$ or higher from all tree methods, and their posterior probability was 1.00; superscript 1 indicates amoeba infecting western Long Island Sound lobsters. Values for nodes that scored all bootstrap values lower that $60 \%$ and posterior probability $<1.00$ are not shown. Note that all branches leading to outgroups were shortened to one-third of their original length (these branches are in bold)

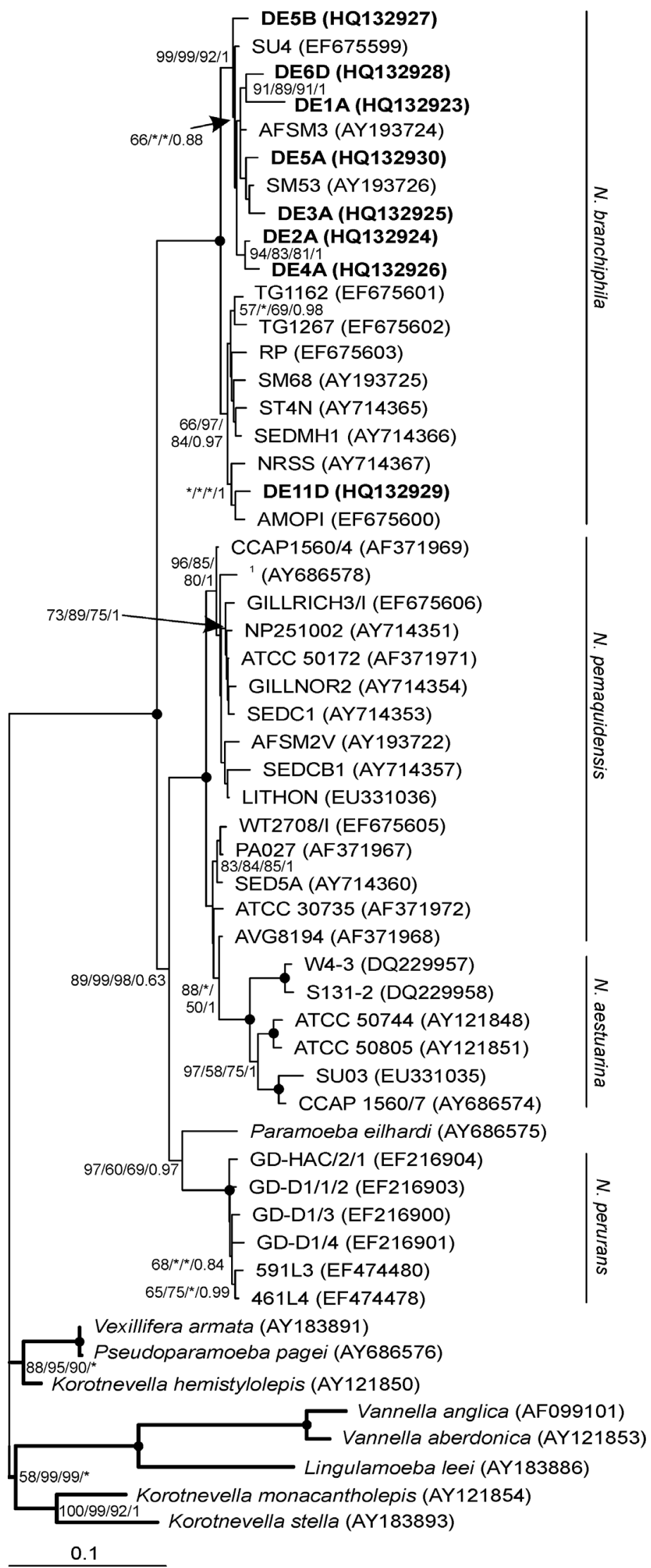


Table 1. Average sequence identities among and within Neoparamoeba species

\begin{tabular}{|c|c|c|c|c|}
\hline pen & $\begin{array}{l}N . \\
\text { naquidensis }\end{array}$ & $\begin{array}{l}\text { N. aestu- } \\
\text { arina }\end{array}$ & $\begin{array}{l}N . \text { pe- } \\
\text { rurans }\end{array}$ & $\begin{array}{l}\text { N. bran- } \\
\text { chiphila }\end{array}$ \\
\hline N. pemaquidensis & 97.8 & 94.2 & 90.3 & 88.9 \\
\hline N. aestuarina & - & 95.9 & 88.6 & 88.0 \\
\hline N. perurans & - & - & 96.6 & 87.5 \\
\hline N. branchiphila & - & - & - & 96.5 \\
\hline
\end{tabular}

\section{DISCUSSION}

Trophozoites of Neoparamoeba strains isolated from Diadema aff. antillarum do not differ in their morphology from environmental or fish- and invertebrateisolated Neoparamoeba strains (Dyková et al. 2003, 2005,2007 ). Also, their fine structure is absolutely consistent with that previously described for Neoparamoeba strains mentioned in 'Results' above. The results of phylogenetic analysis of SSU rDNA that identified the studied sea urchin strains of $N$. branchiphila are supported by the molecular proof of a close relationship between kinetoplastid endosymbionts of DE11D and DE4A strains and Perkinsela amoebae (Hollande, 1980) known from other strains of $N$. branchiphila lineage (Dyková et al. 2008)

The results of the present study and our previous experience based on isolation of over 40 Neoparamoeba strains of different origin (Dyková et al. 2005, $2007,2008)$ and about 60 strains of other marine freeliving amoebae suggest that Paramoeba spp. are not as frequent as Neoparamoeba spp., nor are they as easy to isolate.

The present isolation of Neoparamoeba branchiphila strains exclusively from coelomic fluid of moribund Diadema aff. antillarum suggests that the amoebae either caused or contributed to the observed disease condition. Similarly, Jones (1985), who sampled radial nerves (with associated water vascular radial canals) in green sea urchins Strongylocentrotus droebachiensis, recovered amoebae only from individuals showing signs of disease. Also, experimental infections by injection of amoebae and by exposure to water containing diseased individuals caused 'paramoebiasis' of echinoids (Jones \& Scheibling 1985, Jellet et al. 1988). Jellet et al. (1988) excluded the effect of toxic products of amoebae by injection of membrane-filtered coelomic fluid from moribund, infected individuals to healthy ones; however, pathogenesis of this echinoid 'paramoebiasis' remained obscure: nothing but the activation of autolytic changes and production of degradative enzymes was mentioned as the possible mechanism of this disease.
Almost simultaneously with the above-mentioned early research of amoebic aetiology of sea urchin mortalities, some studies focused on the cause of necrotic lesions on the sea urchin tests (Maes \& Jangoux 1984) or on the diversity and pathogenicity of microorganisms isolated from the affected areas of tests (Gilles \& Pearse 1986). In light of the fact that necrotic lesions of sea urchins reported during mortality episodes were occasionally also observed on individuals within 'healthy' populations (Pearse et al. 1977, Maes \& Jangoux 1984, Scheibling 1984), they can be considered as primary lesions that form an entry gate for amoeba infection.

The study by Gilles \& Pearse (1986) clearly showed that the presence of a mixture of bacteria in water environment makes it extremely difficult to determine the proper agent of lesions. Lesions similar to those described from naturally infected sea urchins were induced experimentally by Vibrio anguillarum and Aeromonas salmonicida (Gilles \& Pearse 1986).

The current effort to establish farming centers for breeding and production of edible sea urchins (Tajima et al. 2007) revives the issue of sea urchin diseases in wild populations. Damage to wild populations may result in the loss of a resource, decreased biodiversity, and a shift in the ecological balance, as exemplified by post-hurricane amoebic disease outbreaks in sea urchins in Nova Scotia (Scheibling et al. 2010).

The lack of consistent comparable data on pathogenesis of sea urchin disease in previous outbreaks, the nature of data from the present study, and the fact that Neoparamoeba branchiphila has previously been isolated from 2 species of healthy sea urchins (Paracentrotus lividus and Heliocidaris erythrogramma; see Dyková et al. 2007) currently make a final conclusion on what was the primary agent of Diadema aff. antillarum mortality impossible. In our opinion, the future study of sea urchin disease manifested by the loss of spines, exfoliation of epidermis, and lesions on the test should consider a possible synergy of both free-living agents, bacteria, and amoebae.

Acknowledgements. The authors are grateful to Dr. J. C. Hernández, Dr. S. Clemente, and Dr. A. Brito from the Grupo de investigación en Biodiversidad, Ecología Marina y Conservación (BIOECOMAC), Department of Animal Biology (Marine Sciences), Faculty of Biology, University of La Laguna, for assistance in the collection of specimens and for allowing us the use of their aquarium facilities. J.L.M. was funded by a postdoctoral grant from the Fundación Canaria Dr. Manuel Morales, La Palma, Canary Islands, Spain. Financial support was provided by the Grant Agency of the Czech Republic (524/09/0137), Ministry of Education, Youth and Sports of the Czech Republic (MSM 6007665801) and research projects of the Institute of Parasitology, Biology Centre of the Academy of Sciences of the Czech Republic (Z60220518 and LC522). 


\section{LITERATURE CITED}

Dyková I, Figueras A, Peric Z (2000) Neoparamoeba Page, 1987: light and electron microscopic observation on six strains of different origin. Dis Aquat Org 43:217-223

Dyková I, Fiala I, Lom J, Lukes J (2003) Persinsiella amoebaelike endosymbiont of Neoparamoeba spp., relatives of the kinetoplastid Ichthyobodo. Eur J Protistol 39:37-52

Dyková I, Nowak BF, Crosbie PBB, Fiala I and others (2005) Neoparamoeba branchiphila n. sp., and related species of the genus Neoparamoeba Page, 1987: morphological and molecular characterization of selected strains. J Fish Dis 28: 49-64

Dyková I, Nowak B, Pecková H, Fiala I, Crosbie P, Dvořáková H (2007) Phylogeny of Neoparamoeba strains isolated from marine fish and invertebrates as inferred from SSU rDNA sequences. Dis Aquat Org 74:57-65

Dyková I, Fiala I, Pecková H (2008) Neoparamoeba spp. and their eukaryotic endosymbionts similar to Perkinsela amoebae (Hollande, 1980): coevolution demonstrated by SSU rRNA gene phylogenies. Eur J Protistol 44:269-277

Fiala I, Dyková I (2003) Molecular characterisation of Neoparamoeba strains isolated from gills of Scophthalmus maximus. Dis Aquat Org 55:11-16

Gilles KW, Pearse JS (1986) Disease in sea urchins Strongylocentrotus purpuratus: experimental infection and bacterial virulence. Dis Aquat Org 1:105-114

Grell KG (1961) Über den 'Nebenkörper' von Paramoeba eilhardi Schaudinn. Arch Protistenkd 105:303-312

Grell KG, Benwitz G (1966) Die Zellhülle von Paramoeba eilhardi Schaudin. Z Naturforsch 21:600-601

Grell KG, Benwitz G (1970) Ultrastruktur mariner Amöben I. Paramoeba eilhardi Schaudin. Arch Protistenkd 112: 119-137

Hall TA 1999. BioEdit: a user-friendly biological sequence alignment editor and analysis program for Windows 95/ 98/NT. Nucl Acids Symp Ser 41:95-98

Hollande A (1980) Identification du parasome (Nebenkern) de Janickina pigmentifera à un symbionte (Perkinsiella amoebae nov. gen. nov. sp.) apparente aux flagelles kinétoplastidies. Protistologia 16:613-625

Jellett JF, Wardlaw AC, Scheibling RE (1988) Experimental infection of the echinoid Strongylocentrotus droebachiensis with Paramoeba invadens: quantitative changes in the coelomic fluid. Dis Aquat Org 4:149-157

Johnson PT (1977) Paramoebiasis in the blue crab, Callinectes sapidus. J Invertebr Pathol 29:308-320

Jones GM (1985) Paramoeba invadens n. sp. (Amoebida, Paramoebidae), a pathogenic amoeba from the sea urchin, Strongylocentrotus droebachiensis, in eastern Canada. J Protozool 32:564-569

Jones GM, Scheibling RE (1985) Paramoeba sp. (Amoebida,

Editorial responsibility: Dieter Steinhagen,

Hannover, Germany
Paramoebidae) as the possible causative agent of sea urchin mass mortality in Nova Scotia. J Parasitol 71: 559-565

Larkin MA, Blackshields G, Brown NP, Chenna R and others (2007) Clustal W and Clustal X version 2.0. Bioinformatics 23:2947-2948

Maes P, Jangoux M (1984) The bald-sea-urchin disease: a biopathological approach. Helgol Meersunters 37: 217-224

Mullen TE, Nevis KR, O'Kelly CJ, Gast RJ, Frasca S Jr (2005) Nuclear small-subunit ribosomal RNA gene-based characterization, molecular phylogeny and PCR detection of the Neoparamoeba from western Long Island Sound lobster. J Shellfish Res 24:719-733

Mullen TE, Russell S, Tucker MT, Maratea JL and others (2004) Paramoebiasis associated with mass mortality of American lobster Homarus americanus in Long Island Sound, USA. J Aquat Anim Health 16:29-38

Page FC (1987) The classification of naked Amoebae (Phylum Rhizopoda). Arch Protistenkd 133:199-217

Pearse JS, Costa DP, Yellin MB, Agegian CR (1977) Localized mass mortality of red sea urchin, Strongylocentrotus franciscanus, near Santa Cruz, California. Fish Bull US 75: 645-648

Perkins FO, Castagna M (1971) Ultrastructure of the Nebenkörper or 'secondary nucleus' of the parasitic amoeba Paramoeba perniciosa (Amoebida, Paramoebidae). J Invertebr Pathol 17:186-193

> Ronquist F, Huelsenbeck JP (2003) MrBayes 3: Bayesian phylogenetic inference under mixed models. Bioinformatics 19:1572-1574

Scheibling RE (1984) Echinoids, epizootics and ecological stability in the rocky subtidal off Nova Scotia, Canada. Helgol Meersunters 37:233-242

Scheibling RE, Feehan C, Lauzon-Guay JS (2010) Disease outbreaks associated with recent hurricanes cause mass mortality of sea urchins in Nova Scotia. Mar Ecol Prog Ser 408:109-116

Sprague V, Beckett RL (1968) The nature of the etiological agent of 'gray crab' disease. J Invertebr Pathol 11:503

Sprague V, Beckett RL, Sawyer TK (1969) A new species of Paramoeba (Amoebida, Paramoebidae) parasitic in the crab Callinectes sapidus. J Invertebr Pathol 14:167-174

Stamatakis A (2006) RAxML-VI-HPC: maximum likelihoodbased phylogenetic analyses with thousands of taxa and mixed models. Bioinformatics 22:2688-2690

Swofford DL (2003) PAUP*: phylogenetic analysis using parsimony ( ${ }^{*}$ and other methods), version 4 . Sinauer Associates, Sunderland, MA

Tajima K, Silva JRMC, Lawrence JM (2007) Disease in sea urchins. In: Lawrence JM (ed) Edible sea urchins: biology and ecology. Dev Aquac Fish Sci 37:67-102

Submitted: January 6, 2011; Accepted: March 17, 2011

Proofs received from author(s): June 9, 2011 